\title{
Indications and Safety of High Flow Nasal Cannula in Pediatric Intensive Care Unit: Retrospective Single Center Experience in Saudi Arabia
}

\author{
Ali Alsuheel Asseri (1D' \\ Youssef Ali AlQahtani ${ }^{1}$ \\ Ahmad Ali Alhanshani' \\ Ghada Haider $\mathrm{Ali}^{2}$ \\ Ibrahim Alhelali ${ }^{2}$
}

'Department of Child Health, College of Medicine, King Khalid University, Abha, Saudi Arabia; ${ }^{2}$ Department of Pediatrics, Abha Maternity and Children Hospital, Abha, Saudi Arabia
Correspondence: Ali Alsuheel Asseri Department of Child Health, College of Medicine, King Khalid University, Abha, Saudi Arabia

Tel +966 500186013; +966 I724I8589

Email alsoheelI I@kku.edu.sa
Background: High flow nasal cannula (HFNC) is a new device for respiratory support. Its use continues to increase in pediatrics as its system is easily set up and well tolerated by patients. We aimed in this study to explore indications and safety of HFNC use and predictors of HFNC failure.

Methods: Hospital records of 92 children with acute respiratory distress admitted to the pediatric intensive care unit (PICU) in Abha Maternity and Children Hospital from January 2018 until March 2020 and received HFNC therapy were studied. A data collection sheet was used that included patients' age, gender, the indication of HFNC, associated chronic diseases, previous admission to PICU, vital signs (initially, 8 hours and 48 hours after using HFNC), outcome after using HFNC, and reasons for HFNC failure.

Results: After receiving HFNC, children's respiratory rate, heart rate, systolic blood pressure, and oxygen saturation improved significantly $(\mathrm{p}<0.001, \mathrm{p}<0.001, \mathrm{p}<0.001, \mathrm{p}=$ 0.005 , and $\mathrm{p}<0.001$, respectively). Regarding laboratory findings, $\mathrm{pH}$ and serum bicarbonate improved significantly ( $\mathrm{p}<0.001$ for both), while $\mathrm{PaCO} 2$ improved but not significantly. The failure rate of HFNC was $23.0 \%$. HFNC failure rates were significantly higher among children with chronic diseases than those with no chronic disease $(33.3 \%$ and $14.9 \%$, respectively, $p=0.038)$ and among children with the air-leak syndrome $(p<0.001)$. After 48 hours of HFNC use, children who experienced HFNC failure had significantly higher respiratory and heart rates $(\mathrm{p}<0.001$ and $\mathrm{p}=0.018$, respectively), lower diastolic blood pressure $(\mathrm{p}=0.011)$, and higher $\mathrm{PaCO} 2(\mathrm{p}<0.001)$.

Conclusion: After HFNC use, significant improvements occur in all clinical parameters and laboratory values of children with respiratory distress, but about one-fourth of cases may experience HFNC failure. Predictors for HFNC failure include underlying chronic disease, low diastolic blood pressure, high respiratory rate, high heart rate, high initial $\mathrm{PaCO} 2$.

Keywords: high flow nasal cannula, respiratory distress, pediatric intensive care, Saudi Arabia

\section{Introduction}

Acute lower respiratory illnesses constitute the leading cause of death among children aged less than five years. Despite the beneficial effects of mechanical ventilation in reducing mortality rates, these technologies are rarely available in many countries due to their high cost and the need for trained personnel for their use. However, the high flow nasal cannula (HFNC), a noninvasive respiratory support tool, proved to be of growing applicability in children with an acute lower respiratory infection (ALRI), hypoxemia, and respiratory distress. ${ }^{1-4}$ 
HFNC is quite safe and an effective treatment option for acute respiratory distress. The HFNC mechanism of action involves decreasing nasopharyngeal resistance, washout of dead space, a reduced inflow of ambient air, and increased airway pressure. ${ }^{5}$ It can reduce the need for intubation and mechanical ventilation in children with severe lower respiratory illness. ${ }^{1,2,4}$ During the last few years, there has been a wide range of HFNC use, especially for patients with severe asthma exacerbation, pneumonia, bronchiolitis, congenital heart disease, and post-extubation respiratory distress. ${ }^{6,7}$ Within 1-2 hours, good responders to HFNC show improvement in their respiratory rate, heart rate, and work of breathing, and reductions in apnea and $\mathrm{O} 2$ requirements. ${ }^{8,9}$ However, if no improvement was observed within this period, another respiratory support and transfer to intensive care unit are deemed. ${ }^{1,2,9}$

Independent risk factors and predictors for HFNC failure include high $\mathrm{FiO} 2$ requirements, previous intubation, cardiac comorbidity, ${ }^{10}$ lack of early oxygenation improvement, ${ }^{1,2}$ low initial $\mathrm{pH}$, and a high initial PaCO2. ${ }^{11}$ In Montreal, Canada, Baudin et al reported an HFNC failure rate of $22 \%$ among children who were admitted to the PICU of the university-affiliated SainteJustine Hospital and were treated with high flow nasal cannula, 3\% received tracheal intubation, while 19\% required to transition to noninvasive ventilation. ${ }^{12}$ However, using HFNC following clinical protocols in PICUs was associated with low complication rates, eg, pneumothorax requiring chest tube insertion (1\%), chest tube-related air leaks (3\%), and significant epistaxis $(0.6 \%){ }^{12}$

Studies on HFNC in Saudi Arabia are scarce. In Riyadh, Saudi Arabia, Tareq et al reported their experience using HFNC at the Pediatric Intensive Care Unit (PICU) of King Faisal Specialist Hospital and Research Center (KFSH-RC). Pneumonia was the main reason for HFNC use $(45.5 \%)$. In their cohort, the failure rate of HFNC was $24.6 \%$. They concluded that HFNC is beneficial for children admitted to pediatric ICU. It reduces the rate of intubation and improves the survival rate. It is a welltolerated device and should be considered as initial respiratory support delivered at pediatric PICU. ${ }^{13}$ In our PICU, we have been using HFNC as the initial respiratory support for children with acute respiratory distress for a couple of years. The present study aimed to explore indications and safety of HFNC use and predictors of HFNC failure.

\section{Methods}

\section{Study Population}

The study included 92 children hospitalized between January 2018 and March 2020 and received HFNC therapy due to acute respiratory distress. Enrolled children aged between 1 month and 12 years old. Patients who presented with shock or intubated without receiving HFNC were excluded. Failure of HFNC was considered if the patient's respiratory condition did not improve or even worsened and the patient needed escalation to noninvasive ventilation or intubation and mechanical ventilation in the intensive care unit. ${ }^{10}$ The decision for discontinuation of HFNC and initiation of mechanical ventilation was based on the clinical and laboratory assessment of the patients by a certified pediatrician.

As per the international guidelines of HFNC use in children, the rate of $30 \mathrm{~L} / \mathrm{min}$ was considered the maximum flow. ${ }^{14}$ Detailed children hospital course was registered, which included death, or successful separation from HFNC, defined as discontinuation of HFNC after more than 48 hours or until PICU discharge. ${ }^{15}$

\section{Study Design and Setting}

The present study followed a retrospective research design. Children were hospitalized at Abha Maternity and Children Hospital (AMCH), Southwest of Saudi Arabia. AMCH is considered tertiary care, referral, and teaching hospital in the southwestern region of the Kingdom of Saudi Arabia. It is a 15-bed medical and surgical pediatric intensive care unit and receives patients from 20 peripheral hospitals.

\section{Data Collection}

We used a data collection sheet that included patients' age, gender, the indication of HFNC, associated chronic diseases, previous admission to PICU, and vital signs (initially, 8 hours, and 48 hours after using HFNC). In addition, the outcomes after using HFNC (clinical improvement or escalation to invasive ventilation) and complications of HFNC (pneumothorax, epistaxis, and severe abdominal distension).

\section{Statistical Analysis}

The Statistical Package for Social Sciences (IBM-SPSS, version 25) was used for data entry and statistical analysis. The Shapiro-Wilk test was used to study variables' normality. Quantitative variables were presented as mean $\pm \mathrm{SD}$, while categorical variables were presented as 
frequency and percentage. For comparing results of the HFNC failure group with those of the HFNC failure group, a chi-square test was applied to compare categorical variables, while an independent sample $t$-test was used to compare quantitative variables. Moreover, repeated measures analysis of variance test was applied to assess the significance of the change in quantitative variables (clinical and laboratory findings) after 8 and 48 hours. Significant differences were considered at p-values less than 0.05 .

\section{Ethical Approval}

The study was approved by the Institutional Research Ethics (IRE) board, Abha Maternity and Children Hospital ethical committee, Saudi Arabia. It was carried out according to the Declaration of Helsinki. Patients' informed consents were not needed since this study was a retrospective observational study without any interventions.

\section{Results}

\section{Demographics of the Enrolled Subjects}

Table 1 shows that $48.9 \%$ of participant children were less than 12 months old, and 56.5\% were males. Associated chronic diseases were present among $48.9 \%$ of children, including underlying congenital heart diseases, bronchial asthma, and chronic respiratory insufficiency due to cerebral palsy and neuromuscular disorders. The most common indications for HFNC were bronchopneumonia alone $(40.2 \%)$ or associated with bronchiolitis (13\%), while $12 \%$ had severe asthma exacerbation, and $23.9 \%$ were post-extubation. More than half of participant children $(56.5 \%)$ received $\mathrm{FiO} 2$ less than $50 \%$, while $39.1 \%$ of children received $\mathrm{FiO} 250-60 \%$. The duration of hospital stays of $19.6 \%$ was $1-7$ days, that of $39.1 \%$ was $8-14$ days, while that of $15.2 \%$ was $15-21$ days, and that of $26.1 \%$ was more than 21 days. Regarding the duration of stay at PICU, $57.6 \%$ stayed for $1-7$ days, $17.4 \%$ was $8-14$ days, while $8.7 \%$ was $15-21$ days, and $16.3 \%$ was more than 21 days. About one-fourth of children (27.2\%) were previously admitted to PICU. About one-fifth of children (23\%) failed HFNC and underwent tracheal intubation. The readmission to the PICU occurred in $15.2 \%$ of those who needed HFNC.

\section{The Initial Clinical Characteristics and Laboratory Parameters of the Patients}

Table 2 shows that after receiving HFNC, respiratory rate, heart rate, systolic blood pressure, and oxygen saturation
Table I Demographics and Clinical Characteristics of the Enrolled Patients

\begin{tabular}{|c|c|}
\hline Characteristics & n (\%) \\
\hline \multicolumn{2}{|l|}{ Age groups } \\
\hline$<12$ months & $45(48.9)$ \\
\hline $\mathrm{I}-5$ years & $35(38.0)$ \\
\hline 5 years & $12(13.0)$ \\
\hline Gender, male, No. (\%) & $52(56.5)$ \\
\hline Associated chronic diseases & $45(48.9)$ \\
\hline \multicolumn{2}{|l|}{ Indication for HFNC use } \\
\hline Bronchopneumonia & $37(40.2)$ \\
\hline Bronchopneumonia + bronchiolitis & $12(13.0)$ \\
\hline Post-extubation & $22(23.9)$ \\
\hline Severe asthma exacerbation & $11(12.0)$ \\
\hline Others & $10(10.9)$ \\
\hline \multicolumn{2}{|l|}{ Fraction of inspired oxygen ( $\mathrm{FiO} 2)$} \\
\hline$<50 \%$ & $52(56.5)$ \\
\hline $50-60 \%$ & $36(39.1)$ \\
\hline$>60 \%$ & $4(4.3)$ \\
\hline \multicolumn{2}{|l|}{ Duration of hospital stay } \\
\hline I-7 days & $18(19.6)$ \\
\hline 8-14 days & $36(39.1)$ \\
\hline$|5-2|$ days & $14(15.2)$ \\
\hline$>21$ days & $24(26.1)$ \\
\hline \multicolumn{2}{|l|}{ Duration of stay at PICU } \\
\hline I-7 days & $53(57.6)$ \\
\hline 8-14 days & $16(17.4)$ \\
\hline$|5-2|$ days & $8(8.7)$ \\
\hline$>21$ days & $15(16.3)$ \\
\hline Previous admission to PICU & $25(27.2)$ \\
\hline \multicolumn{2}{|l|}{ Complications } \\
\hline Air leak syndrome & $8(8.7)$ \\
\hline Death & $9(9.8)$ \\
\hline \multicolumn{2}{|l|}{ Interventions } \\
\hline Tracheal intubation & $21(23.0)$ \\
\hline Chest tube insertion & $8(8.7)$ \\
\hline \multicolumn{2}{|l|}{ Outcome } \\
\hline Success & 71 (77.0) \\
\hline Failure & $21(23.0)$ \\
\hline
\end{tabular}

Abbreviations: HFNC, High Flow Nasal Cannula; FiO2, Fraction of inspired oxygen; PICU, Pediatric Intensive Care Unit.

of children at PICU improved significantly $(\mathrm{p}<0.001, \mathrm{p}<$ $0.001, \mathrm{p}<0.001, \mathrm{p}=0.005$ and $\mathrm{p}<0.001$, respectively), after 8 hours of receiving HFNC. Regarding laboratory findings, $\mathrm{pH}$ and serum bicarbonate improved significantly ( $p<0.001$ for both) after 8 hours of receiving HFNC, while $\mathrm{PaCO} 2$ improved but not significantly $(\mathrm{p}=0.069)$. 
Table 2 Clinical and Laboratory Findings of Enrolled Children at Different Timing of HFNC Initiation (Pre-HFNC and POST-HFNC at 8 and 48 Hours)

\begin{tabular}{|l|c|c|c|c|}
\hline Variables, Mean \pm SD & Initially & After 8 Hours & After 48 Hours & P value \\
\hline RR (per minute) & $5 I .2 \pm I I .8$ & $4 I .5 \pm 9.5$ & $40.0 \pm 10.8$ & $<0.00 I^{*}$ \\
$\mathrm{HR}($ per minute) & $139.7 \pm 25.8$ & $123.2 \pm 19.2$ & $12 I .9 \pm 22.7$ & $<0.00 I^{*}$ \\
$\mathrm{SBP}(\mathrm{mmHg})$ & $103.5 \pm 16.8$ & $97.0 \pm 14.1$ & $96.9 \pm 14.4$ & $<0.00 I^{*}$ \\
$\mathrm{DBP}(\mathrm{mmHg})$ & $59.2 \pm 13.1$ & $56.1 \pm 14.3$ & $53.5 \pm I I .5$ & $0.005^{*}$ \\
Oxygen saturation & $90.7 \pm I I .1$ & $97.3 \pm 3.9$ & $97.0 \pm 4.1$ & $<0.00 I^{*}$ \\
$\mathrm{PH}$ & $7.35 \pm 0.08$ & $7.39 \pm 0.07$ & $7.4 I \pm 0.06$ & $<0.00 I^{*}$ \\
$\mathrm{PaCO}(\mathrm{mmHg})$ & $39.3 \pm 9.7$ & $37.4 \pm 10.3$ & $37.0 \pm 7.9$ & 0.069 \\
Serum bicarbonate $(\mu \mathrm{mol} / \mathrm{L})$ & $21.4 \pm 3.9$ & $22.5 \pm 3.8$ & $23.4 \pm 3.7$ & $<0.00 I^{*}$ \\
\hline
\end{tabular}

Note: $* \mathrm{P}<0.05$ (significant).

Abbreviations: HFNC, High Flow Nasal Cannula; SD, Standard Deviation; RR, Respiratory Rate; HR, Heart Rate; SBP, Systolic Blood Pressure; DBP, Diastolic Blood Pressure; $\mathrm{PaCO}_{2}$, Partial pressure of carbon dioxide.

\section{Characteristics of Patients with Failed and Succeeded HFNC Intervention}

Table 3 shows that failure rates for HFNC did not differ significantly according to child's age, gender, indication for $\mathrm{HFNC}$ use, received $\mathrm{FiO}_{2}$, or previous admission to PICU. The failure rate for HFNC was significantly higher among children with chronic diseases than those with no chronic disease $(33.3 \%$ and $14.9 \%$, respectively, $\mathrm{p}=0.038)$. Failure rates for HFNC were significantly higher among children with a hospital stay or stayed at PICU for more than two weeks ( $p<0.001$ for both).

\section{Comparisons Between the Initial 8 Hours and 48 Hours Clinical and Laboratory Parameters of Patients with Failed and Succeeded HFNC Intervention}

Table 4 shows that the respiratory rate (Mean \pm SD) of children after 48 hours of HFNC administration was significantly higher among those with HFNC failure than those with HFNC success (47.5 \pm 14.9 and $37.6 \pm 7.9 \%$, respectively, $\mathrm{p}<$ $0.001)$. Heart rate (Mean $\pm \mathrm{SD}$ ) of children after 48 hours of HFNC administration was significantly higher among those with HFNC failure than those with HFNC success (131.9 \pm 22.5 and $118.8 \pm 22.0$, respectively, $\mathrm{p}=0.018$ ). Diastolic blood pressure (Mean \pm SD) of children after 48 hours of HFNC administration was significantly lower among those with HFNC failure than those with HFNC success (48.1 \pm 10.7 and $55.1 \pm 11.3$, respectively, $p=0.011$ ). Levels of partial pressure of carbon dioxide $(\mathrm{Mean} \pm \mathrm{SD})$ of children after 8 and 48 hours of HFNC administration were significantly higher among those with HFNC failure than those with
HFNC success $(44.2 \pm 11.5$ and $42.4 \pm 9.8$ vs $35.3 \pm 9.0$ and $35.4 \pm 6.5$, respectively, $\mathrm{p}<0.001$ for both). Serum levels of bicarbonate (Mean $\pm \mathrm{SD}$ ) of children after 8 and 48 hours of HFNC administration were significantly higher among those with HFNC failure than those with HFNC success $(23.9 \pm 4.8$ and $25.4 \pm 5.2$ vs $22.0 \pm 3.3$, and $22.8 \pm 2.9, \mathrm{p}=0.042$, and $\mathrm{p}=0.003$, respectively).

\section{Adverse Effects of HFNC in Our Study}

In our cohort, there were nine deaths, all of which had severe cardiopulmonary comorbidities. Furthermore, they required prolonged PICU admission and intubation for several days following the failure of the HFNC. Due to severe air leak syndrome, eight patients required chest tube insertions. The pneumothorax occurred in one of the HFNC patients, while the other patients were intubated.

\section{Discussion}

The present study revealed that the main indications for HFNC utilization at PICU were respiratory distress due to bronchopneumonia, bronchiolitis, severe asthma exacerbation, or post-extubation. It has been noted that within 8 hours after HFNC use, there were significant improvements in all clinical and laboratory findings of children who received HFNC. However, few complications were reported, eg, air leak syndrome (8.7\%) and death (9.8\%).

Invasive ventilation becomes indicated when respiratory support with HFNC seems inadequate. However, invasive ventilation frequently has a high risk for subsequent complications, such as ventilator-associated pneumonia, airway stenosis, sepsis, acute respiratory distress syndrome, atelectasis, or pulmonary edema. ${ }^{16-18}$ However, HFNC has recently 
Table 3 Clinical Characteristics of Patients by HFNC Status (Non-Failure vs Failure)

\begin{tabular}{|c|c|c|c|c|c|}
\hline \multirow[t]{2}{*}{ Variables } & \multicolumn{2}{|c|}{$\begin{array}{l}\text { Non-Failure } \\
\qquad(n=7 I)\end{array}$} & \multicolumn{2}{|c|}{$\begin{array}{l}\text { Failure } \\
(n=21)\end{array}$} & \multirow[t]{2}{*}{$P$ value } \\
\hline & No. & $\%$ & No. & $\%$ & \\
\hline \multicolumn{6}{|l|}{ Age groups } \\
\hline$<12$ months & 34 & 75.6 & 11 & 24.4 & \\
\hline $\mathrm{I}-5$ years & 26 & 74.3 & 9 & 25.7 & 0.812 \\
\hline$>5$ years & 10 & 83.3 & 2 & 16.7 & \\
\hline \multicolumn{6}{|l|}{ Gender } \\
\hline Male & 39 & 75.0 & 13 & 25.0 & \\
\hline Female & 31 & 77.5 & 9 & 22.5 & 0.780 \\
\hline \multicolumn{6}{|l|}{$\begin{array}{l}\text { Associated chronic } \\
\text { diseases }\end{array}$} \\
\hline No & 40 & 85.1 & 7 & 14.9 & \\
\hline Yes & 30 & 66.7 & 15 & 33.3 & $0.038^{*}$ \\
\hline \multicolumn{6}{|l|}{ Indication for HFNC use } \\
\hline Bronchopneumonia & 28 & 75.7 & 9 & 24.3 & \\
\hline $\begin{array}{l}\text { Bronchopneumonia+ } \\
\text { bronchiolitis }\end{array}$ & 9 & 100.0 & 0 & 0.0 & \\
\hline $\begin{array}{l}\text { Severe asthma } \\
\text { exacerbation }\end{array}$ & 5 & 62.5 & 3 & 37.5 & \\
\hline Post-extubation & 8 & 66.7 & 4 & 33.3 & 0.283 \\
\hline Status asthmaticus & 3 & 100.0 & 0 & 0.0 & \\
\hline Others & 6 & 60.0 & 4 & 40.0 & \\
\hline \multicolumn{6}{|l|}{$\mathrm{FiO}_{2}$} \\
\hline$<50 \%$ & 41 & 78.8 & 11 & 21.2 & \\
\hline $50-60 \%$ & 27 & 75.0 & 9 & 25.0 & 0.420 \\
\hline$>60 \%$ & 2 & 50.0 & 2 & 50.0 & \\
\hline \multicolumn{6}{|l|}{ Duration of hospital stay } \\
\hline I-7 days & 16 & 88.9 & 2 & II.I & \\
\hline 8-14 days & 36 & 100.0 & 0 & 0.0 & \\
\hline$|5-2|$ days & 10 & 71.4 & 4 & 28.6 & $<0.00 I^{*}$ \\
\hline$>21$ days & 8 & 33.3 & 16 & 66.7 & \\
\hline \multicolumn{6}{|l|}{ Duration of stay at PICU } \\
\hline I-7 days & 49 & 92.5 & 4 & 7.5 & \\
\hline 8-14 days & 15 & 93.8 & 1 & 6.3 & \\
\hline$|5-2|$ days & 4 & 50.0 & 4 & 50.0 & $<0.001 *$ \\
\hline$>21$ days & 2 & 13.3 & 13 & 86.7 & \\
\hline \multicolumn{6}{|l|}{ Previous admission to } \\
\hline No & 50 & 74.6 & 17 & 25.4 & \\
\hline Yes & 20 & 80.0 & 5 & 20.0 & 0.591 \\
\hline \multicolumn{6}{|l|}{ Air leak syndrome } \\
\hline No & 69 & 82.1 & 15 & 17.9 & \\
\hline Yes & 1 & 12.5 & 7 & 87.5 & $<0.00 I^{*}$ \\
\hline
\end{tabular}

Note: $* \mathrm{P}<0.05$ (significant).

Abbreviations: HFNC, High Flow Nasal Cannula; FiO2, Fraction of inspired oxygen; PICU, Pediatric Intensive Care Unit. gained rapid global adoption and became well documented in intensive and emergency health-care settings. ${ }^{19,20}$

Several studies have indicated that HFNC is a simple, well-tolerated noninvasive respiratory support. ${ }^{1,2,20}$ It improves gas exchange and flushes anatomical dead space, and decreases work of breathing. ${ }^{21}$ Therefore, HFNC is considered the primary respiratory support for patients with hypoxemic acute respiratory failure across ages. ${ }^{21}$ Coletti et al stated that HFNC could be started as the first-line management for several diseases among children, such as bronchial asthma, or pneumonia, with a low failure rate of $10.1 \%$, necessitating either noninvasive ventilation $(5.6 \%)$ or required intubation (4.5\%). ${ }^{6}$ However, a recent study reported that the effectiveness of HFNC as initial respiratory support among children with moderate-to-severe acute viral bronchiolitis was less than that of nasal continuous positive airway pressure (nCPAP). ${ }^{22}$ They suggested that nCPAP may be more efficient than HFNC for initial respiratory support in young infants hospitalized in a PICU for moderate-to-severe acute viral bronchiolitis. Nevertheless, respiratory support with either nCPAP or HFNC is relatively safe, with very low intubation rates, air leak syndrome, or death. ${ }^{22}$

Moreover, HFNC can be used for patients in several clinical environments, such as emergency departments, inter-hospital transport, or intensive care units. It is reasonably simple to set up, with a single interface, only two settings (gas-flow and $\mathrm{FiO} 2$ ), and no synchronization. ${ }^{23}$

The failure rate for HFNC utilization in our study was $23.9 \%$. Several studies have reported that the overall failure rate for HFNC therapy in the PICU and pediatric emergency department are $30 \%$ and $39 \%$, respectively. ${ }^{24,25}$

Our study indicated that failure rates for HFNC in children admitted to PICU were characterized by the presence of associated chronic disease and those with the hospital stay more than two weeks. In addition, lower diastolic blood pressure, higher respiratory and heart rates at 48 hours, and elevated initial $\mathrm{PaCO} 2$.

Several studies described children with failed HFNC as younger, those with tachypnea, high $\mathrm{PaCO} 2$, a low initial venous $\mathrm{pH}$ less than $7.30,{ }^{11,26}$ experienced no improvement in heart rate, ${ }^{27}$ or respiratory rate, ${ }^{26}$ and those with respiratory acidosis. ${ }^{9,11,26}$ On the other hand, Schibler et al reported that predictors of HFNC success were a significant and rapid decrease in heart rate from baseline within 60 min of HFNC initiation and similarly significant improvement in respiratory rate. ${ }^{19}$ 
Table 4 Vital Signs and Laboratory Characteristics of Patients by HFNC Status (Non-Failure vs Failure)

\begin{tabular}{|c|c|c|c|c|c|}
\hline \multirow[t]{2}{*}{ Variables, Mean \pm SD } & \multicolumn{2}{|c|}{ Non-Failure $(n=71)$} & \multicolumn{2}{|c|}{ Failure $(n=2 I)$} & \multirow[t]{2}{*}{$P$ value } \\
\hline & Mean & SD & Mean & SD & \\
\hline $\mathrm{RR} / \min$ (initial) & 50.5 & 11.9 & 53.3 & 11.4 & 0.328 \\
\hline $\mathrm{RR} /$ min (after 48 hours) & 37.6 & 7.9 & 47.5 & 14.9 & $<0.001 *$ \\
\hline $\mathrm{HR} / \min$ (initial) & 138.7 & 24.2 & 143.0 & 30.7 & 0.498 \\
\hline $\mathrm{HR} / \min$ (after 48 hours) & 118.8 & 22.0 & 131.9 & 22.5 & $0.018^{*}$ \\
\hline $\mathrm{DBP}(\mathrm{mm} / \mathrm{Hg}$, after 48 hours $)$ & 55.1 & 11.3 & 48.1 & 10.7 & $0.01 I^{*}$ \\
\hline $\mathrm{PaCO} 2(\mathrm{~mm} / \mathrm{Hg}$, initial) & 38.7 & 10.0 & 41.4 & 8.9 & 0.250 \\
\hline $\mathrm{PaCO} 2(\mathrm{~mm} / \mathrm{Hg}$, after 8 hours $)$ & 35.3 & 9.0 & 44.2 & 11.5 & $<0.001 *$ \\
\hline $\mathrm{PaCO} 2(\mathrm{~mm} / \mathrm{Hg}$, after 48 hours $)$ & 35.4 & 6.5 & 42.4 & 9.8 & $<0.001 *$ \\
\hline HCO3 (mmol/L, initial) & 21.0 & 3.7 & 22.5 & 4.1 & 0.109 \\
\hline HCO3 (mmol/L, after 8 hours) & 22.0 & 3.3 & 23.9 & 4.8 & $0.042^{*}$ \\
\hline $\mathrm{HCO} 3$ (mmol/L, after 48 hours) & 22.8 & 2.9 & 25.4 & 5.2 & $0.003 *$ \\
\hline
\end{tabular}

Note: $* \mathrm{P}<0.05$ (significant).

Abbreviations: HFNC, High Flow Nasal Cannula; SD, Standard Deviation; RR, Respiratory Rate; HR, Heart Rate; DBP, Diastolic Blood Pressure; PaCO2, Partial pressure of carbon dioxide; $\mathrm{HCO} 3$, Serum bicarbonate.

In our study, the most common indications for HFNC were bronchopneumonia associated with bronchiolitis, severe asthma exacerbation, and children with respiratory distress post-extubation. Several studies reported similar indications, including asthma, ${ }^{25}$ bronchiolitis, ${ }^{4,22,26-28}$ pneumonia, ${ }^{11}$ congenital heart diseases, ${ }^{29}$ and postextubation with respiratory distress. ${ }^{30}$ HFNC utilization is associated with decreased intubation rates, reduced respiratory distress, and increased oxygenation saturation. ${ }^{19,31,32}$

Compared with CPAP, HFNC use in the PICU and neonatal ICU is associated with better tolerance, reduced nasal/mucosal injury, ease of use, fewer complications, and lower cost. ${ }^{30,33,34}$ Baudin and Pouyau stressed that HFNC is generally used and preferred more than nCPAP by many clinicians, who strongly prefer to use HFNC due to its perceived benefits over nCPAP, eg, greater comfort, higher simplicity, and more effectiveness. ${ }^{20}$ Therefore, HFNC found its place in the hearts of many physicians, including pediatric intensivists and respiratory therapists.

The study has several limitations. First, the study is a retrospective study and was conducted in a single center, which increased the chance of bias and limited the study generalization. Also, we did not include a scoring system to classify the severity of patient's illnesses at the beginning of the HFNC initiation.

\section{Conclusion}

The main indications for HFNC utilization for children admitted to the PICU in Abha Maternity and Children Hospital are bronchopneumonia, bronchiolitis, status asthmaticus, or post-extubation. After HFNC use, significant improvements occur in all clinical and laboratory results. However, few complications may occur, eg, air leak syndrome, or death. About one-fourth of cases may experience HFNC failure. Predictors associated with HFNC failure include the presence of chronic disease, hospital stays more than two weeks, having air leak syndrome, low diastolic blood pressure, high respiratory rate, high heart rate, and high $\mathrm{PaCO} 2$.

\section{Acknowledgments}

The authors would like to express their gratitude to all of the health-care professionals at Ahba Maternity and Children Hospital's PICU who have dedicated their lives to caring for critically ill children. The authors would also like to express their gratitude to Dr. Samar Abousadegh for contributing to the data collection. Furthermore, we are extremely grateful to the study's participants.

\section{Disclosure}

The authors declare no conflicts of interest for this work.

\section{References}

1. Kwon JW. High-flow nasal cannula oxygen therapy in children: a clinical review. Clin Exp Pediatr. 2020;63(1):3-7. doi:10.3345/ kjp.2019.00626

2. Mikalsen IB, Davis P, Øymar K. High flow nasal cannula in children: a literature review. Scand J Trauma Resusc Emerg Med. 2016;24 (1):93. doi:10.1186/s13049-016-0278-4

3. Luo J, Duke T, Chisti MJ, Kepreotes E, Kalinowski V, Li J. Efficacy of high-flow nasal cannula vs standard oxygen therapy or nasal continuous positive airway pressure in children with respiratory distress: a meta-analysis. $J$ Pediatr. 2019;215:199-208. doi:10.1016/j. jpeds.2019.07.059

4. Fainardi V, Abelli L, Muscarà M, Pisi G, Principi N, Esposito S. Update on the role of high-flow nasal cannula in infants with bronchiolitis. Children. 2021;8(2):66. doi:10.3390/children8020066 
5. Möller W, Feng S, Domanski U, et al. Nasal high flow reduces dead space. J Appl Physiol. 2017;122(1):191-197. doi:10.1152/ japplphysiol.00584.2016

6. Coletti KD, Bagdure DN, Walker LK, Remy KE, Custer JW. Highflow nasal cannula utilization in pediatric critical care. Respir Care. 2017;62(8):1023-1029. doi:10.4187/respcare.05153

7. Guillot C, Le Reun C, Behal H, et al. First-line treatment using high-flow nasal cannula for children with severe bronchiolitis: applicability and risk factors for failure. Arch Pediatr. 2018;25(3):213-218. doi:10.1016/j.arcped.2018.01.003

8. Lodeserto FJ, Lettich TM, Rezaie SR. High-flow nasal cannula: mechanisms of action and adult and pediatric indications. Cureus. 2018;10(11):e3639.

9. Slain KN, Shein SL, Rotta AT. The use of high-flow nasal cannula in the pediatric emergency department. J Pediatr. 2017;93(Suppl 1):36-45. doi:10.1016/j.jped.2017.06.006

10. Betters KA, Gillespie SE, Miller J, Kotzbauer D, Hebbar KB. High flow nasal cannula use outside of the ICU; factors associated with failure. Pediatr Pulmonol. 2017;52(6):806-812. doi:10.1002/ppul.23626

11. Kelly GS, Simon HK, Sturm JJ. High-flow nasal cannula use in children with respiratory distress in the emergency department: predicting the need for subsequent intubation. Pediatr Emerg Care. 2013;29(8):888-892. doi:10.1097/PEC.0b013e31829e7f2f

12. Baudin F, Gagnon S, Crulli B, Proulx F, Jouvet P, Emeriaud G. Modalities and complications associated with the use of high-flow nasal cannula: experience in a pediatric ICU. Respir Care. 2016;61 (10):1305-1310. doi:10.4187/respcare.04452

13. Tareq A, Chahdah S, Moath A, et al. Pediatric high flow nasal cannula experience in a tertiary care hospital in Saudi Arabia. Am J Pediatr. 2020;6(3):182-189. doi:10.11648/j.ajp.20200603.13

14. Milési C, Boubal M, Jacquot A, et al. High-flow nasal cannula: recommendations for daily practice in pediatrics. Ann Intensive Care. 2014;4:29. doi:10.1186/s13613-014-0029-5

15. Rodriguez M, Thille AW, Boissier F, et al. Predictors of successful separation from high-flow nasal oxygen therapy in patients with acute respiratory failure: a retrospective monocenter study. Ann Intensive Care. 2019;9(1):101. doi:10.1186/s13613-019-0578-8

16. Principi T, Fraser DD, Morrison GC, et al. Complications of mechanical ventilation in the pediatric population. Pediatr Pulmonol. 2011;46(5):452-457. doi:10.1002/ppul.21389

17. Martins LDS, Ferreira AR, Kakehasi FM. Adverse events related to mechanical ventilation in a pediatric intensive care unit. Rev Paul Pediatr. 2021;39:e2019180. doi:10.1590/1984-0462/2021/39/2019180

18. Mukhtar B, Siddiqui NR, Haque A. Clinical characteristics and immediate-outcome of children mechanically ventilated in PICU of Pakistan. Pak J Med Sci. 2014;30(5):927-930.

19. Schibler A, Pham TM, Dunster KR, et al. Reduced intubation rates for infants after introduction of high-flow nasal prong oxygen delivery. Intensive Care Med. 2011;37(5):847-852. doi:10.1007/ s00134-011-2177-5

20. Wing R, James C, Maranda LS, Armsby CC. Use of high-flow nasal cannula support in the emergency department reduces the need for intubation in pediatric acute respiratory insufficiency. Pediatr Emerg Care. 2012;28(11):1117-1123. doi:10.1097/PEC.0b013e31827122a9
21. Baudin F, Pouyau R. High-flow nasal cannula in the pediatric ICU: popular or efficient? Respir Care. 2017;62(8):1116-1117. doi:10.4187/respcare.05720

22. Habra B, Janahi IA, Dauleh H, Chandra P, Veten A. A comparison between high-flow nasal cannula and noninvasive ventilation in the management of infants and young children with acute bronchiolitis in the PICU. Pediatr Pulmonol. 2020;55(2):455-461. doi:10.1002/ppul.24553

23. Schlapbach LJ, Schaefer J, Brady AM, Mayfield S, Schibler A. Highflow nasal cannula (HFNC) support in interhospital transport of critically ill children. Intensive Care Med. 2014;40(4):592-599. doi:10.1007/s00134-014-3226-7

24. Ten Brink F, Duke T, Evans J. High-flow nasal prong oxygen therapy or nasopharyngeal continuous positive airway pressure for children with moderate-to-severe respiratory distress?. Pediatr Crit Care Med. 2013;14(7):e326-e331. doi:10.1097/PCC.0b013e31828a894d

25. Long E, Babl FE, Duke T. Is there a role for humidified heated high-flow nasal cannula therapy in paediatric emergency departments? Emerg Med J. 2016;33(6):386-389. doi:10.1136/ emermed-2015-204914

26. Abboud PA, Roth PJ, Skiles CL, Stolfi A, Rowin ME. Predictors of failure in infants with viral bronchiolitis treated with high-flow, high-humidity nasal cannula therapy. Pediatr Crit Care Med. 2012;13(6):e343-e349. doi:10.1097/PCC.0b013e31825b546f

27. Mayfield S, Bogossian F, O’Malley L, Schibler A. High-flow nasal cannula oxygen therapy for infants with bronchiolitis: pilot study. J Paediatr Child Health. 2014;50(5):373-378. doi:10.1111/jpc.12509

28. Hilliard TN, Archer N, Laura H, et al. Pilot study of vapotherm oxygen delivery in moderately severe bronchiolitis. Arch Dis Child. 2012;97(2):182-183. doi:10.1136/archdischild-2011-301151

29. Testa G, Iodice F, Ricci Z, et al. Comparative evaluation of high-flow nasal cannula and conventional oxygen therapy in paediatric cardiac surgical patients: a randomized controlled trial. Interact Cardiovasc Thorac Surg. 2014;19(3):456-461. doi:10.1093/icvts/ivu171

30. Collins CL, Holberton JR, Barfield C, Davis PG. A randomized controlled trial to compare heated humidified high-flow nasal cannulae with nasal continuous positive airway pressure postextubation in premature infants. J Pediatr. 2013;162(5):949-954.e1. doi:10.1016/j. jpeds.2012.11.016

31. Bressan S, Balzani M, Krauss B, Pettenazzo A, Zanconato S, Baraldi E. High-flow nasal cannula oxygen for bronchiolitis in a pediatric ward: a pilot study. Eur J Pediatr. 2013;172 (12):1649-1656. doi:10.1007/s00431-013-2094-4

32. Spentzas T, Minarik M, Patters AB, Vinson B, Stidham G. Children with respiratory distress treated with high-flow nasal cannula. $J$ Intensive Care Med. 2009;24(5):323-328. doi:10.1177/0885066609340622

33. Yoder BA, Stoddard RA, Li M, King J, Dirnberger DR, Abbasi S. Heated, humidified high-flow nasal cannula versus nasal CPAP for respiratory support in neonates. Pediatrics. 2013;131(5):e1482e1490. doi:10.1542/peds.2012-2742

34. Manley BJ, Owen LS, Doyle LW, et al. High-flow nasal cannulae in very preterm infants after extubation. $N$ Engl J Med. 2013;369 (15):1425-1433. doi:10.1056/NEJMoa1300071
Pediatric Health, Medicine and Therapeutics

\section{Publish your work in this journal}

Pediatric Health, Medicine and Therapeutics is an international, peerreviewed, open access journal publishing original research, reports, editorials, reviews and commentaries. All aspects of health maintenance, preventative measures and disease treatment interventions are addressed within the journal. Practitioners from all disciplines are invited to submit their work as well as healthcare researchers and patient support groups. The manuscript management system is completely online and includes a very quick and fair peer-review system. Visit http://www.dovepress.com/testimonials.php to read real quotes from published authors. 